\title{
O processo de liderar sob influência da tecnologia: Principais potencialidades e
}

\section{fragilidades}

\author{
The process of leading under the influence of technology: Main potentialities and fragilities \\ El proceso de liderazgo bajo la influencia de la tecnología: Principales potencialidades y \\ fragilidades
}

Recebido: 05/04/2021 | Revisado: 12/04/2021 | Aceito: 13/04/2021 | Publicado: 26/04/2021

\author{
Rogério Carvalho de Figueredo \\ ORCID: https://orcid.org/0000-0003-3349-4812 \\ Universidade Federal de Goiás, Brasil \\ E-mail: rigoh1@live.com \\ Renata Cristina Correia da Silva Amorim \\ ORCID: https://orcid.org/0000-0002-7568-4182 \\ Universidad Columbia del Paraguay, Paraguay \\ E-mail: renatacsamorim@gmail.com \\ Leidiany Souza Silva \\ ORCID: https://orcid.org/0000-0001-9734-3699 \\ Instituto Educacional Santa Catarina, Brasil \\ E-mail: leidianysouza@hotmail.com \\ Karla Camila Correia da Silva \\ ORCID: https://orcid.org/0000-0003-1538-7028 \\ Instituto Educacional Santa Catarina, Brasil \\ E-mail: karlacamilac@yahoo.com.br \\ Kênia Alessandra de Araújo Celestino \\ ORCID: https://orcid.org/0000-0002-3811-1043 \\ Faculdade Estácio de Sá de Goiás, Brasil \\ E-mail: celestino.kenia@gmail.com \\ Amanda Pereira Alves \\ ORCID: https://orcid.org/0000-0002-3115-6169 \\ Secretaria Municipal de Saúde de Presidente Kennedy, Brasil \\ E-mail: amandinha_2alves@hotmail.com
}

\begin{abstract}
Resumo
Introdução: A tecnologia tem impactado a vida das pessoas e das organizações de trabalho, de forma direta ou indireta influenciando suas relações e produtividade, de forma positiva e negativa, exigindo dos líderes competências compatíveis a essa evolução. Objetivo: Identificar a influência da tecnologia no processo de liderança, bem como suas potencialidades e fragilidades no contexto de trabalho. Metodologia: Trata-se de uma revisão integrativa da literatura, exploratória, descritiva, de abordagem qualitativa, que utilizou artigos, dissertações e e-books publicados entre 2016 e 2020. Os materiais foram extraídos do SciELO, Google Acadêmico, Biblioteca Virtual da Fundação Getúlio Vargas e repositórios institucionais. Discussão Teórica: A partir da seleção, organização e análise das obras científicas foi possível discorrer sobre a relação entre tecnologia, sociedade e mundo do trabalho; as principais características do líder do século XXI e a influência da tecnologia; as principais potencialidades e fragilidades da tecnologia no processo de liderar. Considerações Finais: A tecnologia pode ser considerada como influente meio de potencializar e/ou fragilizar a atuação do líder e no processo de trabalho das organizações. Ressalta-se a importância de sua utilização de forma ética e humanizada.
\end{abstract}

Palavras-chave: Liderança; Tecnologia; Potencialidades; Fragilidades.

\begin{abstract}
Introduction: Technology has impacted the lives of people and work organizations, directly or indirectly, influencing their relationships and productivity, in a positive and negative way, requiring leaders compatible with this evolution. Objective: To identify the influence of technology in the leadership process, as well as its strengths and weaknesses in the work context. Methodology: This is an integrative literature review, exploratory, descriptive, with a qualitative approach, which used articles, dissertations and e-books published between 2016 and 2020. The materials were extracted from SciELO, Google Scholar, Virtual Library of Fundação Getúlio Vargas and institutional repositories. Theoretical Discussion: From the selection, organization and analysis of scientific works it was possible to discuss the relationship between technology, society and the world of work; the main characteristics of the 21 st century leader and the influence of technology; the main strengths and weaknesses of technology in the process of leading. Final
\end{abstract}


Considerations: Technology can be considered as an influential means to enhance and / or weaken the performance of the leader and in the work process of organizations. The importance of its use in an ethical and humanized way is emphasized.

Keywords: Leadership; Technology; Potentialities; Weaknesses.

\section{Resumen}

Introducción: La tecnología ha impactado la vida de las personas y organizaciones laborales, directa o indirectamente, incidiendo en sus relaciones y productividad, de manera positiva y negativa, requiriendo líderes compatibles con esta evolución. Objetivo: Identificar la influencia de la tecnología en el proceso de liderazgo, así como sus fortalezas y debilidades en el contexto laboral. Metodología: Se trata de una revisión bibliográfica integradora, exploratoria, descriptiva, con enfoque cualitativo, que utilizó artículos, disertaciones y libros electrónicos publicados entre 2016 y 2020. Los materiales fueron extraídos de SciELO, Google Scholar, Biblioteca Virtual de la Fundación Getúlio Vargas y repositorios institucionales. Discusión Teórica: A partir de la selección, organización y análisis de trabajos científicos, fue posible discutir la relación entre tecnología, sociedad y mundo del trabajo; las principales características del líder del siglo XXI y la influencia de la tecnología; las principales fortalezas y debilidades de la tecnología en el proceso de liderazgo. Consideraciones finales: La tecnología se puede considerar como un medio influyente para mejorar y / o debilitar el desempeño del líder y en el proceso de trabajo de las organizaciones. Se enfatiza la importancia de su uso de forma ética y humanizada.

Palabras clave: Liderazgo; Tecnología; Potencialidades; Debilidades.

\section{Introduçãa}

O contexto das organizações e a dinâmica dos processos de trabalho mudaram significativamente no decorrer da última década em decorrência da constante evolução tecnológica e de inovação, que invadem a rotina das profissões e implicam em suas relações e produtividade. Essas mudanças são referenciadas à Quarta Revolução Industrial, que utiliza como meio de produção a internet e inúmeras ferramentas digitais, exigindo assim a criação ou reinvenção de postos de trabalho, além de novas habilidades profissionais (Cruz \& Neto, 2020).

Com o acelerado avanço das Tecnologias da Informação e Comunicação (TICs) surgiram novas formas organizacionais do trabalho, em que equipes virtuais, distantes entre si e dispersas geograficamente, mas reunidas por meios tecnológicos, estão substituindo as tradicionais equipes que se reúnem diariamente em um mesmo local para cumprirem sua jornada de trabalho (Stocker, 2018).

O processo de liderar no âmbito de trabalho das organizações, sejam elas públicas ou privadas, também passa por constantes transformações, principalmente na transição do modelo tradicional em liderar face-a-face para o modelo virtual denominado como e-leadership (Stocker, 2018). Porém, mesmo com esses novos cenários, ainda é de grande importância compreender que a liderança trata-se de uma competência e não um cargo hierárquico dentro de uma organização (Balsanelli, 2017).

Há controvérsias acerca da influência e dos impactos da tecnologia no âmbito das organizações, nas rotinas de trabalho, assim como nas relações interpessoais e sociais, visto que a tecnologia representa uma forma de produção que agrega diferentes instrumentos, recursos e artifícios, de modo a organizar e preservar os vínculos sociais no campo das forças de trabalho. Com isso, as habilidades e inabilidades dos líderes nesse processo, constituem indicativos de incorporação as transformações vivenciadas, e podem ser decisórias para evolução e produtividade (Bovério et al, 2018).

Paralelamente, a influência da tecnologia na sociedade se relaciona ao poder e controle que ela pode proporcionar. E quando não existe acesso ao desenvolvimento tecnológico de forma democrática, a diferenciação e exclusão social surgem e ocasionam diversos prejuízos. Vale ressaltar que a maioria das tecnologias são desenvolvidas para ampliar a eficácia e a eficiência do meio organizacional, e podem ser potentes aliadas para o processo de liderança. Porém, quando não são distribuídas e utilizadas de forma equânime acarretam insegurança, desconfiança, preocupação, falhas de comunicação, sobrecarga, estresse e conflitos (Bovério et al, 2018). 
Diante da problemática apresentada surge os seguintes questionamentos: "Como a tecnologia pode influenciar o processo de liderar? E quais são as suas potencialidades e fragilidades?".

Este estudo se justifica pela necessidade de ampliar os conhecimentos sobre a temática e por seu potencial para evidenciar a influência da tecnologia nas rotinas de trabalho com ênfase nas atribuições do líder. Assim, pode contribuir para compreensão sobre a utilização da tecnologia nas diversas organizações e grupos de trabalho, subsidiando líderes no planejamento, organização, coordenação e motivação dos seus colaboradores.

O objetivo do presente artigo consiste em identificar a influência da tecnologia no processo de liderança, bem como suas potencialidades e fragilidades no contexto de trabalho, a partir de uma revisão integrativa da literatura.

\section{Metodologia}

Trata-se de uma pesquisa do tipo revisão integrativa da literatura, exploratória, descritiva e de abordagem qualitativa. Este tipo de estudo contribui para o processamento sistemático e analítico de artigos e demais produções científicas, e se caracteriza pela busca de informações sobre o tema, que sintetizem a problemática da pesquisa em busca de ampliar sua clareza e compreensão (Mendes et al, 2019). O percurso metodológico do estudo se deu em 6 (seis) fases, conforme descrição a seguir.

- $\quad 1^{\mathrm{a}}$ fase: Formulação da questão norteadora do estudo, a saber "Como a tecnologia pode influenciar o processo de liderar? E quais são as suas potencialidades e fragilidades?"

- $\quad 2^{\mathrm{a}}$ fase: Levantamento de material científico para embasamento do estudo nas bases eletrônicas Scientific Electronic Library Online (SciELO), Biblioteca Virtual da Fundação Getúlio Vargas, Repositórios Institucionais de Universidades Brasileiras e Google Acadêmico. Foram utilizados os descritores: líder, liderança, tecnologia e trabalho, benefícios da tecnologia no trabalho, prejuízos da tecnologia no trabalho, tecnologia e gestão de pessoas.

- $\quad 3^{\text {a }}$ fase: Aplicação dos critérios de inclusão e exclusão dos materiais encontrados nas bases de dados. Foram incluídos artigos, dissertações, teses e e-books, obrigatoriamente disponíveis por completo, em português ou inglês, publicados nos últimos 4 (quatro) anos compreendendo o período de 2016 a 2020. Foram excluídos materiais incompletos, resumos de anais tanto simples como expandido, produções duplicadas, e publicadas fora do período definido.

- $\quad 4^{\mathrm{a}}$ fase: Avaliação dos materiais identificados a partir dos critérios de inclusão e exclusão. Leitura dos resumos para identificação daqueles que não condizem com o escopo da pesquisa.

- $5^{a}$ fase: Leitura completa e minuciosa dos materiais, onde foi possível organizá-los em tabelas com categorias temáticas específicas. A partir da análise e síntese das informações extraídas de cada material emergiram os capítulos que compõem a discussão teórica desse estudo. Principais informações extraídas e consolidadas: autores, tipo de material, título, metodologia, principais achados e ano de publicação.

- $6^{a}$ fase: Análise do consolidado de informações e escrita do artigo de forma descritiva e qualitativa.

Apresenta-se a seguir (Figura 1), o fluxo de seleção dos estudos, de acordo com cada etapa do percurso metodológico, e os resultados obtidos a partir da estratégia de buscas por materiais. 
Figura 1. Descrição das etapas do percurso metodológico e resultados obtidos.

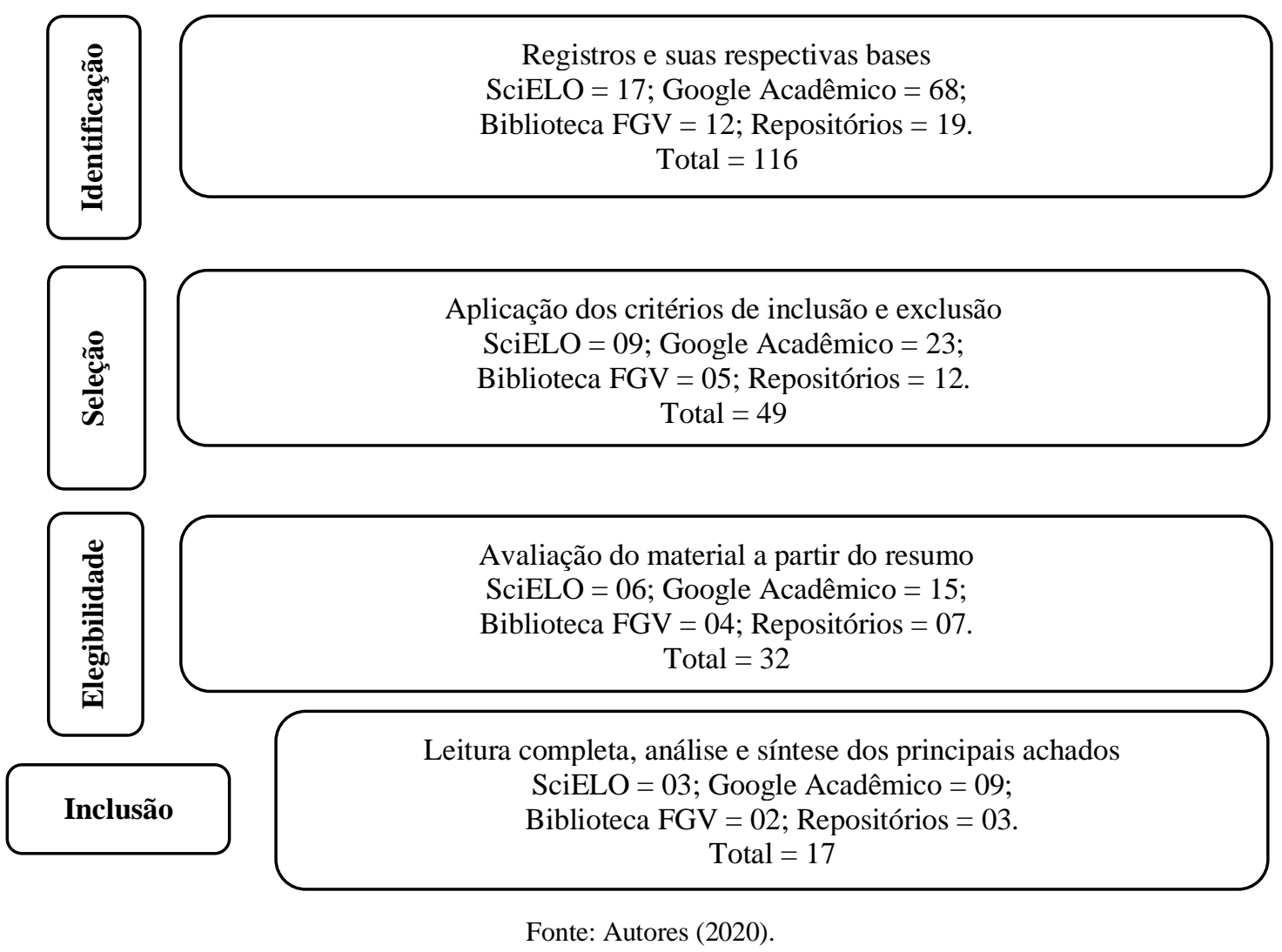

A busca na literatura resultou em um total de 116 materiais sobre a temática deste estudo, e após a aplicação dos critérios de inclusão e exclusão reduziu-se para 49. A partir da avaliação do material com ênfase nos resumos foram considerados 32 estudos como elegíveis. Após leitura completa, análise e síntese dos principais achados, a amostra deste artigo foi constituída por 17 estudos, incluídos em sua discussão teórica.

\section{Discussão Teórica}

Da organização dos estudos incluídos, emergiram as seguintes categorias: tecnologia, sociedade e mundo do trabalho; as principais características do líder do século XXI e a influência da tecnologia; as principais potencialidades e fragilidades da tecnologia no processo de liderar. Estas nortearam a escrita da discussão teórica em seus capítulos correspondentes. As obras que compõem cada categoria estão dispostas nas Tabelas 1, 2 e 3 respectivamente. 
Tabela 1. Identificação dos estudos que relacionam tecnologia, sociedade e mundo do trabalho.

\begin{tabular}{|c|c|c|c|c|c|}
\hline $\mathbf{N}$ & Autores & $\begin{array}{l}\text { Tipo de } \\
\text { material }\end{array}$ & Título da obra & Características do estudo & Ano \\
\hline 1 & $\begin{array}{l}\text { Silva, J. L. } \\
\text { A. }\end{array}$ & Dissertação & $\begin{array}{l}\text { Competências na Era } \\
\text { Digital e Indústria 4.0: o } \\
\text { gestor de tecnologia nos } \\
\text { bancos brasileiros. }\end{array}$ & $\begin{array}{l}\text { Método: Pesquisa de campo a partir de } \\
\text { entrevista. } \\
\text { Principais achados: A tecnologia parece estar } \\
\text { se encaminhando para se transformar uma } \\
\text { competência que todos precisarão possuir em } \\
\text { graus variados, sendo exigência para } \\
\text { competências estruturais e de liderança. }\end{array}$ & 2020 \\
\hline 2 & Gabriel, M. & e-Book & $\begin{array}{l}\text { Você, eu e os robôs: } \\
\text { pequeno manual do } \\
\text { mundo digital. }\end{array}$ & $\begin{array}{l}\text { Método: Livro digital. } \\
\text { Principais achados: Atualmente, são } \\
\text { numerosas as funcionalidades proporcionadas } \\
\text { pelas redes sociais virtuais para facilitar } \\
\text { diversos aspectos da vida dos seus usuários. }\end{array}$ & 2018 \\
\hline 3 & $\begin{array}{l}\text { Bovério, M. } \\
\text { A.; Patino, } \\
\text { M. T. O.; } \\
\text { Amorim, F. } \\
\text { R.; Abreu, P. } \\
\text { H. C. }\end{array}$ & Artigo & $\begin{array}{l}\text { Análise dos impactos da } \\
\text { tecnologia na organização } \\
\text { do trabalho em uma } \\
\text { empresa do setor têxtil. }\end{array}$ & $\begin{array}{l}\text { Método: Revisão bibliográfica e estudo de } \\
\text { caso. } \\
\text { Principais achados: A tecnologia está em } \\
\text { constante desenvolvimento, partindo não } \\
\text { somente de problemas a serem resolvidos na } \\
\text { sociedade, mas também da vontade e } \\
\text { possibilidade de inovar e sofisticar a vida da } \\
\text { população, desde o mais complexo ambiente } \\
\text { de negócio até as atividades mais simples do } \\
\text { cotidiano. }\end{array}$ & 2018 \\
\hline 4 & $\begin{array}{l}\text { Teles, N.; } \\
\text { Caldas, J. C. }\end{array}$ & e-Book & $\begin{array}{l}\text { Tecnologia e Trabalho no } \\
\text { Século XXI: uma } \\
\text { proposta de abordagem. }\end{array}$ & $\begin{array}{l}\text { Método: Revisão bibliográfica. } \\
\text { Principais achados: Sintetiza os diferentes } \\
\text { contributos apresentados, entendidos como } \\
\text { condição analítica para uma abordagem dos } \\
\text { impactos tecnológicos que não sendo centrada } \\
\text { em antecipações acerca dos impactos incertos } \\
\text { no emprego, enfatiza as consequências } \\
\text { realmente experimentadas no processo de } \\
\text { trabalho e no trabalhador, recuperando, ao } \\
\text { mesmo tempo, a dimensão política para o } \\
\text { centro de debate. }\end{array}$ & 2019 \\
\hline 5 & $\begin{array}{l}\text { Lin, X.; } \\
\text { Palazzo, B.; } \\
\text { Yang, F. }\end{array}$ & Artigo & $\begin{array}{l}\text { The risks of old capital } \\
\text { age: Asset pricing } \\
\text { implications of } \\
\text { technology adoption. } \\
\text { (Os riscos da idade do } \\
\text { capital antigo: } \\
\text { implicações de preços de } \\
\text { ativos de } \\
\text { adoção de tecnologia) }\end{array}$ & $\begin{array}{l}\text { Método: Estudo ecológico de abordagem } \\
\text { quantitativa. } \\
\text { Principais achados: As empresas que adotam } \\
\text { tecnologia são menos arriscadas do que as } \\
\text { que não adotam, porque a adoção de } \\
\text { tecnologia cara limita a flexibilidade das } \\
\text { empresas que não a adotam em atualizar seu } \\
\text { antigo capital para a fronteira, causando seu } \\
\text { valor de continuação para estar mais exposto } \\
\text { aos choques de fronteira. }\end{array}$ & 2019 \\
\hline 6 & $\begin{array}{l}\text { Vieira, K. L. } \\
\text { S. S. }\end{array}$ & Artigo & $\begin{array}{l}\text { Evolução tecnológica e a } \\
\text { reestruturação do espaço. }\end{array}$ & $\begin{array}{l}\text { Método: Revisão bibliográfica. } \\
\text { Principais achados: A sociedade atual é } \\
\text { considerada como uma organização em rede, } \\
\text { com processos estruturados de produção, } \\
\text { experiência, poder e comunicação. Essa } \\
\text { estrutura surge como produto da revolução } \\
\text { tecnológica e dos novos padrões sociais, } \\
\text { econômicos e culturais instalados em um } \\
\text { espaço globalizado em que a noção de tempo } \\
\text { e espaço passou a ser essencial para a } \\
\text { eficiência e eficácia da produção e do } \\
\text { consumo. }\end{array}$ & 2019 \\
\hline
\end{tabular}




\section{Tecnologia, sociedade e mundo do trabalho}

O desenvolvimento da tecnologia tem afetado nosso planeta, nosso ambiente profissional, nossa vida social e nosso cotidiano, sendo considerado um fenômeno extremamente relevante à pesquisa. Em todas as fases do desenvolvimento humano, as mudanças causadas pela tecnologia ou ferramentas criadas por ela possuem efeito decisivo em nosso desenvolvimento e afetam todos os aspectos da vida. O progresso tecnológico não é considerado bom nem ruim, mas a sua utilização pode trazer consequências positivas e/ou negativas (Silva, 2020).

Entre os diversos recursos advindos da tecnologia da informação e comunicação, emergiram as redes sociais virtuais, que consistem em plataforma digitais que possibilitam a conexão e troca de informações entre indivíduos sem bloqueios geográficos ou temporais. Essas plataformas fazem parte da rotina da maioria das pessoas, e tem incorporado atividades pessoais e sociais, inclusive no âmbito profissional e de trabalho (Gabriel, 2018).

Nas últimas décadas, em comparação com as do século passado, o desenvolvimento da tecnologia e dos negócios ocorreu de forma muito rápida. Paradigmas foram quebrados e novas oportunidades surgiram, exigindo que todos nós nos adaptemos, onde a hiperconectividade potencializou a adoção de novos comportamentos (Silva, 2020).

A sociedade contemporânea está em constante mudança, principalmente porque a introdução de novas tecnologias de informação afeta diretamente o dia a dia de toda a população. Porém, ao focar no ambiente organizacional moderno, é necessário compreender que essa mudança tecnológica envolve uma série de fatores e estratégias estabelecidas para atingir os objetivos organizacionais, como o aumento da capacidade produtiva (Bovério et al, 2018).

O debate sobre o impacto do desenvolvimento tecnológico no emprego, nos salários e no trabalho teve origem no início da revolução industrial. A posição oposta oscila entre a ideia de que a mecanização irá inevitavelmente destruir empregos e reduzir os salários. Nessa expectativa oposta, as máquinas como fonte de crescimento da produtividade irão aumentar a produtividade e os salários, fornecer mais demanda e, portanto, proporcionar mais oportunidades de emprego (Teles \& Caldas, 2019).

A razão pela qual uma empresa decide investir em recursos tecnológicos é geralmente porque seus processos de trabalho encontram-se desatualizados e obsoletos. Atualmente, para manter ou melhorar sua competitividade e qualidade de suas ações, se faz necessário aprimorar e investir continuamente em seus processos, principalmente por meio da tecnologia (Lin et al, 2019).

A comunicação entre as pessoas, a organização social do trabalho e seus ambientes, as dinâmicas de produção foram modificadas por influência da evolução tecnológica. De acordo com essa evolução, recursos técnico científicos foram criados para atender gradativamente as necessidades e anseios da sociedade. Nesse sentido, o uso das tecnologias de informação e comunicação foi intensificado pela utilização da internet, proporcionando o alcance de bens, serviços e produtos em diversos locais, inclusive distantes do espaço geográfico que estivermos (Vieira, 2019).

De acordo com Vieira (2019) os limites de tempo e espaço foram superados pelas empresas globais por meio das novas tecnologias. Conforme a velocidade dos fluxos e demandas, o espaço é reduzido e a inclusão de novos produtos e serviços no dia a dia das pessoas vai além da simplória relação de compra e venda. Percebe-se que o status, o sentimento de aceitação, homogeneização ou segregação social/espacial influenciam de forma significativa essa relação. 
Tabela 2. Identificação dos estudos que apresentam as principais características do líder do século XXI e a influência da tecnologia.

\begin{tabular}{|c|c|c|c|c|c|}
\hline $\mathbf{N}$ & Autores & $\begin{array}{l}\text { Tipo de } \\
\text { material }\end{array}$ & Título da obra & Características do estudo & Ano \\
\hline 1 & $\begin{array}{l}\text { Nascimento, L. } \\
\text { F. \& Bryto, K. } \\
\text { K. C. }\end{array}$ & Artigo & $\begin{array}{l}\text { A influência da liderança } \\
\text { na produtividade } \\
\text { organizacional: Estudo de } \\
\text { caso na empresa Solus } \\
\text { Tecnologia. }\end{array}$ & $\begin{array}{l}\text { Método: Estudo de caso e revisão bibliográfica. } \\
\text { Principais achados: a liderança é um fator de } \\
\text { influência na produtividade e seu impacto } \\
\text { ocorre conforme o perfil adotado pelo líder, } \\
\text { logo, se a produtividade da equipe possui } \\
\text { frequentes oscilações pode estar ocorrendo um } \\
\text { problema na liderança. }\end{array}$ & 2019 \\
\hline 2 & Stocker, F. & Artigo & $\begin{array}{c}\text { E-Leadership: reflexões e } \\
\text { desafios da liderança } \\
\text { empresarial } \\
\text { contemporânea. }\end{array}$ & $\begin{array}{l}\text { Método: Pesquisa de campo a partir de } \\
\text { entrevistas. } \\
\text { Principais achados: há benefícios por parte das } \\
\text { empresas com a utilização da forma de trabalho } \\
\text { virtual, no entanto há uma lacuna de pesquisas } \\
\text { e informações para entender como se dá a } \\
\text { interação na forma de gestão, a liderança } \\
\text { virtual e sobre esta nova estrutura e dinâmica } \\
\text { organizacional. }\end{array}$ & 2018 \\
\hline 3 & $\begin{array}{c}\text { Besen, F., } \\
\text { Tecchio, E. \& } \\
\text { Fialho, F. A. P. }\end{array}$ & Artigo & $\begin{array}{l}\text { Liderança autêntica e a } \\
\text { gestão do conhecimento. }\end{array}$ & $\begin{array}{l}\text { Método: Revisão bibliográfica. } \\
\text { Principais achados: É uma conduta de liderança } \\
\text { interessante para as organizações intensivas em } \\
\text { conhecimento, visto que se preocupa em criar } \\
\text { um ambiente organizacional positivo e com } \\
\text { foco no desempenho verdadeiro e sustentável. } \\
\text { A ética e autenticidade nas relações podem } \\
\text { favorecer a criação e compartilhamento do } \\
\text { conhecimento. }\end{array}$ & 2017 \\
\hline 4 & $\begin{array}{l}\text { Mcgregor, A., } \\
\text { Magee, C.A., } \\
\text { Caputi, P. \& } \\
\text { Iverson, D. L. }\end{array}$ & Artigo & $\begin{array}{l}\text { A job demands-resources } \\
\text { approach to presenteeism. } \\
\text { (Uma abordagem de } \\
\text { demandas de recursos de } \\
\text { trabalho para o } \\
\text { presenteísmo). }\end{array}$ & $\begin{array}{l}\text { Método: Pesquisa de campo. } \\
\text { Principais achados: Maiores demandas de } \\
\text { trabalho (intimidação no local de trabalho, } \\
\text { pressão de tempo e conflito trabalho-família) e } \\
\text { menores recursos de trabalho (liderança } \\
\text { apenas) foram encontrados para estar } \\
\text { indiretamente relacionados ao presenteísmo via } \\
\text { aumento do esgotamento. Enquanto os maiores } \\
\text { recursos de trabalho (liderança e apoio social) } \\
\text { estavam indiretamente relacionados ao } \\
\text { presenteísmo por meio de um melhor } \\
\text { envolvimento no trabalho. }\end{array}$ & 2016 \\
\hline 5 & $\begin{array}{l}\text { Roman, A. V., } \\
\text { Van Wart, M., } \\
\text { Wang, X. H., } \\
\text { Liu, C., Kim, S. } \\
\text { \& Mccarthy, A. }\end{array}$ & Artigo & $\begin{array}{c}\text { Defining E-leadership as } \\
\text { Competence in ICT- } \\
\text { Mediated } \\
\text { Communications: An } \\
\text { Exploratory Assessment. } \\
\text { (Definindo E-Leadership } \\
\text { como Competência em } \\
\text { Comunicações Mediadas } \\
\text { por TIC: Uma Avaliação } \\
\text { Exploratória) }\end{array}$ & $\begin{array}{l}\text { Método: Revisão bibliográfica. } \\
\text { Principais achados: Acreditamos que com o } \\
\text { aumento da difusão tecnológica dentro espaços } \\
\text { individuais e organizacionais, o papel e a } \\
\text { importância de competências eletrônicas para } \\
\text { liderança que afetam aqueles que realizam a } \\
\text { missão do setor público só vai continuar a } \\
\text { crescer. }\end{array}$ & 2018 \\
\hline 6 & $\begin{array}{l}\text { Silva, A. F. C., } \\
\text { Martins, C. B. \& } \\
\text { Moreira, K. D. }\end{array}$ & Artigo & $\begin{array}{c}\text { Impactos dos recursos } \\
\text { tecnológicos, na atuação } \\
\text { do secretário executivo, } \\
\text { na organização de eventos } \\
\text { científicos. }\end{array}$ & $\begin{array}{l}\text { Método: Pesquisa de campo e revisão } \\
\text { bibliográfica. } \\
\text { Principais achados: a tecnologia impacta, } \\
\text { majoritariamente, de modo positivo na } \\
\text { profissão, embora seja essencial verificar, de } \\
\text { modo pormenorizado, se as ferramentas } \\
\text { tecnológicas disponíveis são compatíveis com } \\
\text { as demandas organizacionais. }\end{array}$ & 2018 \\
\hline
\end{tabular}




\section{As principais características do líder do século XXI e a influência da tecnologia}

Atualmente, liderar é considerado um fator crítico para o êxito organizacional, onde os bons gerentes não são mais suficientes, e âmbito de trabalho requer líderes com habilidades para guiar outras pessoas rumo aos objetivos projetados da instituição, mantendo a harmonia e estimulando a sinergia da equipe. O líder deve agregar valor ao grupo a qual faz parte, e o fazê-lo evoluir, de forma individual e coletiva, incentivando a superação de limites, muitas vezes impostos pela desmotivação ou coordenação deficiente. Portanto, o sucesso do líder é intrínseco ao sucesso dos liderados. (Nascimento \& Bryto, 2019).

Segundo as principais definições do "bom líder", este não se surpreende diante dos desafios e dos resultados alcançados, mas sim à equipe, por ser o primeiro a identificar as dificuldades da rotina de trabalho e orientar os colaboradores para superação, e assim oferecer apoio, demonstrando confiabilidade e disponibilidade à seus liderados (Stocker, 2018).

Além disso, espera-se que o líder seja dotado de conhecimentos acerca de sabedoria, filosofia e psicologia, visto que estes potencializam o trabalho da equipe, envolvendo-os às metas e objetivos organizacionais. As habilidades cognitivas e comportamentais, as competências técnicas e profissionais favorecem as intervenções do líder para solução de problemas, além de influenciar e inspirar os membros de equipe (Stocker, 2018).

Existe diversas abordagens teóricas acerca da liderança, desde as clássicas (comportamentais) às mais contemporâneas (carismática e transformacional), porém é importante ressaltar a diferença entre o que é "líder" e o que é "estilo de liderança". O líder representa o indivíduo a qual de maneira formal ou informal lhe foi atribuído essa posição. O estilo de liderança compreende a forma como este líder atuará junto a sua equipe (Stocker, 2018).

Diante dos acontecimentos das últimas décadas, que caracterizam uma crise ética e moral da sociedade, as organizações estão cada vez mais críticas e atentas ao desenvolvimento de uma liderança com base em princípios, valores e ética, denominada liderança autêntica. Esse tipo de liderança tem como princípio o desejo de treinar e desenvolver líderes que sejam proativos e capazes de criar ambientes positivos de trabalho, que se articulem de forma ética e sejam socialmente responsáveis. Além disso, espera-se que esse líder possua autoconhecimento e estimule a autoconsciência de seus liderados, visando criar relações transparentes e que contribuam para o desenvolvimento de sua equipe (Besen et al, 2017).

Segundo McGregor et al. (2016), devido à internacionalização das empresas, aos novos modelos de equipe profissional e a ampliação dos meios de trabalho que foram impulsionados pela tecnologia da informação e comunicação, a liderança perpassa por um processo de aprimoramento e adaptação contínuos a esse contexto e essas novas configurações. Entre elas, podemos citar o surgimento dos times virtuais que possuem uma nova forma organizacional e de dinâmica de trabalho, em que os liderança é denominada e-leadership (liderança virtual) ou e-liderança.

Os times virtuais consistem em equipes formada por "profissionais do conhecimento", que estão organizacionalmente, geograficamente e/ou temporalmente dispersos, mas reunidos através de tecnologia da informação e comunicação, à nível local, regional, nacional e internacional (Mcgregor et al, 2016).

A e-liderança compreende um campo amplo e recente, que vai além da descrição de como os e-líderes utilizam as tecnologias de informação em seus processos de trabalho. Essa denominação confronta a liderança tradicional, baseada no "face-a-face", por esta não atender e acompanhar os novos desafios impostos às organizações, e pelas varáveis cada vez mais difusas de tempo e espaço. O impacto causado pela tecnologia sobre o comportamento organizacional e na liderança tem se destacado na prática e nas pesquisas científicas (Roman et al, 2018).

O líder em seu contexto organizacional passa a desenvolver competências que devem priorizar a exploração e o aproveitando da tecnologia, tanto auxiliando na condução das suas atribuições, quanto promovendo seu crescimento profissional. Assim, atualmente os recursos tecnológicos impactam profundamente a atuação do líder, independente do seu estilo de liderança (Silva et al, 2018). 
Tabela 3. Identificação dos estudos que evidenciam as principais potencialidades e fragilidades da tecnologia da tecnologia no processo de liderar.

\begin{tabular}{|c|c|c|c|c|c|}
\hline $\mathbf{N}$ & Autores & $\begin{array}{l}\text { Tipo de } \\
\text { material }\end{array}$ & Título da obra & Características do estudo & Ano \\
\hline 1 & $\begin{array}{c}\text { Ronchi, C. C., } \\
\text { Bandeira, N. } \\
\text { P., Oliveira, R. } \\
\text { D., Melo } \\
\text { Júnior, J. S. M. } \\
\text { \& Carvalho, T. } \\
\text { N. }\end{array}$ & Artigo & $\begin{array}{c}\text { Resiliência e } \\
\text { qualidade de vida: } \\
\text { as reverberações } \\
\text { discursivas no } \\
\text { imaginário dos } \\
\text { líderes. }\end{array}$ & $\begin{array}{l}\text { Método: Pesquisa de campo a partir de entrevista. } \\
\text { Principais achados: Pode-se evidenciar que as } \\
\text { lideranças apresentam a resiliência como um fator } \\
\text { preponderante para o processo de liderar, cabendo } \\
\text { ao líder ter a capacidade de adaptação ao meio e de } \\
\text { superar adequadamente as situações adversas. } \\
\text { Também nota-se que o discurso revela certa } \\
\text { contradição e distanciamento entre o que é falado } \\
\text { sobre qualidade de vida e a prática da liderança, } \\
\text { reforçando que o sentido do trabalho assume uma } \\
\text { percepção subjetiva. }\end{array}$ & 2017 \\
\hline 2 & Neto, J. P. B. & e-Book & $\begin{array}{l}\text { Gestão de pessoas } \\
\text { 4.0: liderança e } \\
\text { aprendizado diante } \\
\text { da inteligência } \\
\text { artificial e da } \\
\text { Quarta Revolução } \\
\text { Industrial. }\end{array}$ & $\begin{array}{l}\text { Método: Capítulo de e-book. } \\
\text { Principais achados: é chegado o momento de } \\
\text { reinventarmos a capacidade humana de } \\
\text { aprendizagem em face da irrefreável Quarta } \\
\text { Revolução Industrial, da Inteligência Artificial e da } \\
\text { robotização para gerar valor em redes que } \\
\text { compartilham conhecimentos, desenvolvem } \\
\text { competências, promovem a colaboração e entregam } \\
\text { inovações. }\end{array}$ & 2020 \\
\hline 3 & $\begin{array}{l}\text { Ribeiro, J. S. } \\
\text { A. N., França, } \\
\text { R., Corrêa, F. } \\
\text { \& Ziviani, F. }\end{array}$ & Artigo & $\begin{array}{l}\text { Criação de valor } \\
\text { para indústria } 4.0 \text { : } \\
\text { desafios e } \\
\text { oportunidades para } \\
\text { gestão do } \\
\text { conhecimento e } \\
\text { tecnologia da } \\
\text { informação. }\end{array}$ & $\begin{array}{l}\text { Método: Revisão bibliográfica. } \\
\text { Principais achados: Os atuais ambientes da Indústria } \\
4.0 \text { precisam se concentrar no gerenciamento de } \\
\text { ativos de conhecimento. Os sistemas de informação } \\
\text { facilitam a comunicação aberta para desenvolver } \\
\text { redes de conhecimento que eventualmente levarão à } \\
\text { difusão da inovação para melhorar a } \\
\text { competitividade da organização. }\end{array}$ & 2019 \\
\hline 4 & $\begin{array}{l}\text { César, L. G. D. } \\
\text { \& Neves, L. A. }\end{array}$ & Artigo & $\begin{array}{l}\text { Atuação da gestão } \\
\text { de pessoas no } \\
\text { fortalecimento do } \\
\text { comprometimento } \\
\text { organizacional pós } \\
\text { pandemia: a cultura } \\
\text { organizacional } \\
\text { como caminho. }\end{array}$ & $\begin{array}{l}\text { Método: Ensaio teórico. } \\
\text { Principais achados: O contexto pandêmico ainda } \\
\text { apresenta inúmeras variáveis que vêm modificando } \\
\text { constantemente as relações sociais e econômicas } \\
\text { entre os indivíduos e as organizações. Merece } \\
\text { também destaque a compreensão de que inúmeras } \\
\text { variáveis influenciam no desenvolvimento de uma } \\
\text { gestão de cultura organizacional e do } \\
\text { comprometimento organizacional, portanto, uma } \\
\text { estratégia organizacional demanda uma análise } \\
\text { bastante aprofundada de cada situação, envolvendo } \\
\text { o ambiente interno e externo de cada empresa. }\end{array}$ & 2020 \\
\hline 5 & $\begin{array}{l}\text { Rocha, C. T. } \\
\text { M. \& Amador, } \\
\text { F. S. }\end{array}$ & Artigo & $\begin{array}{l}\text { O teletrabalho: } \\
\text { conceituação e } \\
\text { questões para } \\
\text { análise. }\end{array}$ & $\begin{array}{l}\text { Método: Revisão bibliográfica. } \\
\text { Principais achados: O teletrabalho é uma tendência } \\
\text { no atual cenário do mundo do trabalho. Se, por um } \\
\text { lado, propagam-se os benefícios às empresas, aos } \\
\text { trabalhadores e à sociedade, por outro, também } \\
\text { existe uma série de riscos envolvidos, dizendo } \\
\text { respeito, principalmente, à individualização do } \\
\text { trabalho - que pode acarretar o isolamento social, } \\
\text { profissional e político dos trabalhadores. }\end{array}$ & 2018 \\
\hline
\end{tabular}

Fonte: Autores (2020).

\section{As principais potencialidades e fragilidades da tecnologia no processo de liderar}

Diante de um frenético ritmo e um aumento significativo da carga horária de trabalho na atualidade, evidencia-se uma maior complexidade no processo de administrar e liderar. E a verificação das competências dos líderes diante dessas 
complexidades impõe a capacidade de assimilar aspectos biopsicossociais. Devido as pressões de produção, a adesão quase indispensável de novas tecnologias e de diferentes arranjos na dinâmica de trabalho, as relações sociais encontram-se cada vez mais fragilizadas. Nesse contexto, os avanços tecnológicos representam o principal influenciador dessa fragmentação do homem físico e emocional, ocasionando consequências positivas e negativas em colaboradores, equipes e organizações. No que tange o líder, este está duplamente suscetível, pois ora sofre cobranças e ora é cobrador (Ronchi et al, 2017).

A partir desse argumento, a tecnologia tem sido utilizada pelas organizações como ferramenta para ampliar o domínio sobre a vida dos seus colaboradores, além dos muros organizacionais. Percebe-se um aumento de reféns corporativos, que se sentem intimados a aumentar o seu ritmo de trabalho para além do que é definido em contrato de trabalho. É possível exemplificar o uso indiscriminado do celular, de e-mail, das redes sociais, além do aproveitamento da mão-de-obra para projetos de responsabilidade social, entre outras (Ronchi et al, 2017).

Embora as novas tecnologias estejam assumindo tarefas operacionais no âmbito de trabalho e solucionando problemas de rotina sem a intervenção do ser humano, os líderes se beneficiam disso para desenvolver sua equipe, delegando-lhes atribuições mais complexas e estratégicas. Nesse processo, a Inteligência Artificial também oferece aos líderes apoio para tomada de decisões de forma mais assertiva e ágil (Neto, 2020).

$\mathrm{O}$ processo de liderança imenso à tecnologia estimula as pessoas a serem mais flexíveis, criativas e impacta significativamente em sua inteligência, pois a colaboração em rede, desenvolvida a partir dos recursos tecnológicos, é uma prática de rotina que impulsiona as realizações grupais, denominado pela literatura como "swarm intelligence" ou inteligência de enxame. Trata-se de uma remodelagem do processo de trabalho de forma artificial, mas que operam de forma natural e efetiva, a exemplo temos o Facebook e o Google, entre outros (Neto, 2020).

Uma das principais vantagens da tecnologia para o processo de liderar consiste em sua potencialidade como facilitador na gestão do conhecimento, a partir do que se possui e o que é gerado, por conseguinte. A gestão do conhecimento abrange a identificação e análise do conhecimento existente, para fim de planejamento e controle de novas ações que gerem novos conhecimentos (Ribeiro et al, 2019).

Os avanços tecnológicos ampliaram as possibilidades para o teletrabalho, e com o advento da pandemia esse crescimento ficou ainda mais evidente dentro das organizações. Vale ressaltar, que além disso, outros fatores influenciaram essa mudança como: redução de custos, disponibilidade e acesso, melhoria da qualidade na conexão de internet, aumento da competitividade no mercado, entre outros (César \& Neves, 2020).

Diante disso, pode-se identificar de modo geral que as principais potencialidades da tecnologia no processo de liderar estão relacionadas à: flexibilidade da jornada de trabalho; à possibilidade de organização do horário e da forma de trabalho para conciliar as demandas laborais, familiares e sociais e de lazer; a redução de tempo e economia financeira com o deslocamento entre casa e o local de trabalho; o estímulo e instrumentalização para a autonomia da produção individual e coordenação dos colaboradores, entre outros (Rocha \& Amador, 2018).

Os impactos caracterizados como potencializadores também beneficiam as organizações, como na redução de custos com espaço físico, equipamentos e manutenção dos mesmos; progressão da produtividade; identificação e absorção de talentos; e diminuição do absenteísmo (Rocha \& Amador, 2018).

Quanto as fragilidades, os autores Rocha \& Amador (2018) sintetizam como preocupante a dependência da tecnologia tanto para o líder como para a organização. Para o processo de liderança, considera-se mais difícil gerenciar as equipes tecnológicas ou de forma virtual, se comparadas às tradicionais, principalmente pela relação e comunicação não ser face-aface, mas sim por meios eletrônicos. Evidencia-se dispersões temporais, físicas e culturais entre os colaboradores, e até mesmo entre os líderes, na qual se tornam um grande desafio para a dinâmica de trabalho. Além disso, ainda há risco acerca da regulamentação do trabalho, quando não se consegue distinguir os espaços e tempos de vida laboral, familiar, pessoal e social, 
trazendo assim repercussões negativas nos modos de sociabilidade dos trabalhadores, e em sua saúde.

\section{Considerações Finais}

Diante da Quarta Revolução Industrial e do contínuo avanço tecnológico, e toda sua influência no mundo do trabalho, considera-se que a preocupação das organizações e seus líderes não deve residir na tentativa de deter a tecnologia, mas sim em sua utilização de forma ética e humanizada, em que os processos de trabalhos sejam definidos a partir da gestão de pessoas e pela tomada de decisão que estimule líderes e colaboradores. Os novos líderes "digitais" de modo geral apresentam facilidade para aprender, atualizar e exercer a liderança, porém precisarão de muita competência para interagir e integrar pessoas e ferramentas tecnológicas, com vistas a agregar e gerar valor na construção de um mundo melhor.

Sugere-se o desenvolvimento de novos estudos sobre a temática, de forma mais ampla e sistemática, que possam refletir a realidade empírica e assim permitir uma análise mais aprofundada sobre o contexto de trabalho, as implicações para liderança na contemporaneidade, e a influência da tecnologia na rotina e produção laboral.

\section{Referências}

Balsanelli, A. P. (2017). Liderança em enfermagem: Desafios e possibilidades. Acta Paulista de Enfermagem, 30(1), enero-febrero. https://www.redalyc.org/pdf/3070/307050739001.pdf

Besen, F., Tecchio, E., \& Fialho, F. A. P. (2017). Liderança autêntica e a gestão do conhecimento. Gest. Prod., São Carlos, 24(1), 2-14. https://www.scielo.br/pdf/gp/v24n1/0104-530X-gp-0104-530X898-13.pdf

Bovério, M. A., Patino, M. T. O., Amorim, F. R. \& Abreu, P. H. C. (2018). Análise dos impactos da tecnologia na organização do trabalho em uma empresa do setor têxtil. Ciências Sociais Aplicadas em Revista - UNIOESTE/MCR - 18(34), 66-83. http://e-revista.unioeste.br/index.php/csaemrev ista/article/view/19481/12689

César, L. G. D. \& Neves, L. A. (2020). Atuação da gestão de pessoas no fortalecimento do comprometimento organizacional pós pandemia: a cultura organizacional como caminho. Revista Valore, 5: 192-205. https://revistavalore.emnuvens.com.br/valore/article/view/656/457

Cruz, M. T. S. \& Neto, J. P. B. (2020). Impactos da inteligência artificial na gestão de pessoas. Tikibooks, 186 p.; Il. https://www.pucsp.br/sites/default/files/download/graduacao/cursos/administracao/livro-impactos-da-inteligencia-artificial-na-gestao-de-pessoas.pdf\#page=14

Gabriel, M. (2018). Você, eu e os robôs: pequeno manual do mundo digital. Atlas.

Lin, X., Palazzo, B. \& Yang, F. (2019). The risks of old capital age: asset pricing implications of technology adoption. Journal of monetary economics. June 13;12:25. https://doi.org/10.1016/j.jmoneco.2019.06.001

Mcgregor, A., Magee, C.A., Caputi, P. \& Iverson, D. L. (2016). A job demands-resources approach to presenteeism. Career Development International, 21(4), 402-418. https://doi.org/10.1108/CDI-01-2016-0002

Mendes, K. D. S., Silveira, R. C. C. P. \& Galvão, C. M. (2019). Uso de gerenciador de referências bibliográficas na seleção dos estudos primários em revisão integrativa. Texto Contexto Enferm. 28:e20170204. https://www.scielo.br/pdf/tce/v28/pt_1980-265X-tce-28-e20170204.pdf

Nascimento, L. F. \& Bryto, K. K. C. (2019). A influência da liderança na produtividade organizacional: Estudo de caso na empresa Solus Tecnologia. Revista de Administração e Contabilidade da Faculdade Estácio do Pará - Belém 6(11), 31-44, http://www.revistasfap.com/ojs3/index.php/rac/article/view/257/225

Neto, J. P. B. (2020). Gestão de pessoas 4.0: liderança e aprendizado diante da inteligência artificial e da Quarta Revolução Industrial. Impactos da inteligência artificial na gestão de pessoas. Tikibooks, 186 p.; Il. https://www.pucsp.br/sites/default/files/download/graduacao/cursos/administracao/livroimpactos-da-inteligencia-artificial-na-gestao-de-pessoas.pdf\#page $=14$

Ribeiro, J. S. A. N., França, R., Corrêa, F. \& Ziviani, F. (2019). Criação de valor para indústria 4.0: desafios e oportunidades para gestão do conhecimento e tecnologia da informação. Congresso Internacional de Conhecimento e Inovação - ciki, [S. l.], 1(1). https://proceeding.ciki.ufsc.br/index .php/ciki/article/view/693

Rocha, C. T. M. \& Amador, F. S. (2018). O teletrabalho: conceituação e questões para análise. Cad. EBAPE.BR, 16(1) https://www.scielo.br/pdf/cebape/v16n1/1679-3951-cebape-16-01-152.pdf

Ronchi, C. C., Bandeira, N. P., Oliveira, R. D., Melo Júnior, J. S. M. \& Carvalho, T. N. (2017). Resiliência e qualidade de vida: as reverberações discursivas no imaginário dos líderes. Latin American Journal of Business Management. 8(2), 19-39, https://lajbm.com.br/index.php/jou $\mathrm{rnal} / \mathrm{article} / \mathrm{view} / 424$

Roman, A. V., Van Wart, M., Wang, X. H., Liu, C., Kim, S. \& Mccarthy, A. (2018). Defining E-leadership as Competence in ICT-Mediated Communications: An Exploratory Assessment. Public Administration Review, p.1-14. https://doi.org/10.1111/puar.12980

Silva, A. F. C., Martins, C. B. \& Moreira, K. D. (2018). Impactos dos recursos tecnológicos, na atuação do secretário executivo, na organização de eventos científicos. Revista Capital Científico - 16(3). Jul/Set. https://revistas.unicentro.br/index.php/capitalcientifico/article/view/5269/pdf 
Research, Society and Development, v. 10, n. 5, e4410514672, 2021

(CC BY 4.0) | ISSN 2525-3409 | DOI: http://dx.doi.org/10.33448/rsd-v10i5.14672

Silva, J. L. A. (2020). Competências na Era Digital e Indústria 4.0: o gestor de tecnologia nos bancos brasileiros. Dissertação de Mestrado em Administração. Pontifícia Universidade Católica de São Paulo. https://tede.pucsp.br/bitstream/handle/23094/2/Jos\%c3\%a9\%20Luiz\%20Al ves\%20da\%20Silva.pdf

Stocker, F. (2018). E-Leadership: reflexões e desafios da liderança empresarial contemporânea. Revista Expectativa, 17(2). http://saber.unioeste.br/index.php/expectativa/article/view/20493/13862

Teles, N. \& Caldas, J. C. (2019). Tecnologia e Trabalho no Século XXI: uma proposta de abordagem. Cadernos do Observatório \#12. Centro de Estudos Sociais. Universidade de Coimbra. 12, 33p. https://eg.uc.pt/handle/10316/87022

Vieira, K. L. S. S. (2019). Evolução tecnológica e a reestruturação do espaço. Revista Artigos.Com, 3, e1118, https://www.acervomais.com.br/inde x.php/artigos /articl e/view/1118 